\title{
Correlation of Glycated Hemoglobin and Iron Deficiency Anemia among Diabetic and Non Diabetic Patients
}

\author{
Vydehi Veeramalla ${ }^{1}$ and Swetha Madas ${ }^{2 *}$ \\ ${ }^{1}$ Consultant Biochemist, Anupama Hospital, KPHB colony, Kukutpalli, \\ Hyderabad, Telangana, India \\ ${ }^{2}$ Department of TB and Chest, RVM Institute of Medical Sciences and Research Centre, \\ Hyderabad, Telangana, India \\ *Corresponding author
}

\begin{abstract}
A B S T R A C T
Hemoglobin A1c (HbA1c), also known as glycated hemoglobin can be used as an indicator of a patient's glycemic status for over a previous 3 months. Iron deficiency anemia (IDA) is one of the most prevalent forms of malnutrition. Reduced iron stores are

\section{Keywords}

Glycated hemoglobin, Iron deficiency anemia, Diabetic patients, Non-diabetic patients.

\section{Article Info}

Accepted: 19 October 2017 Available Online: 10 December 2017 shown to have a direct link with increased glycation of hemoglobin A1C (HbA1c), thereby leading to false-high values of HbA1c in the non-diabetic individuals. 98 diabetic patients and 86 non diabetic patients with anemia were included into the study. Hemoglobin levels, mean corpuscular hemoglobin $(\mathrm{MCH})$, mean corpuscular hemoglobin concentration $(\mathrm{MHCH})$, mean corpuscular volume (MCV), hematocrit, platelet count, total blood picture, differential leucocyte count was done for all samples. Samples from patients were tested for serum ferritin and haemoglobin at base line, 1 month and 2 months following iron treatment. Out of the total 98 diabetic patients, $42.9 \%$ were males and $57 \%$ were females. Among the non-diabetes also, the predominant gender were females $58.1 \%$ and males were $41.9 \%$. The most common type of anemia among the diabetic patients was severe, seen in $66.3 \%$ cases, followed by moderate in 31.6. At baseline the hemoglobin in the anemic patients was $6.3 \mathrm{~g} / \mathrm{dL}$, while the serum ferritin was $7.3 \mathrm{mg} / \mathrm{ml}$ and $\mathrm{HbA} 1 \mathrm{c}$ was $6.2 \%$ and $12.1 \mathrm{~g} / \mathrm{dL}, 259 \mathrm{mg} / \mathrm{ml}$ and $5.1 \%$ respectively after 2 months of treatment with iron supplements. The HbA1c levels showed considerable reduction after the treatment. Thus, whenever HbA1c is calculated to detect the glycemic status of a patient, factors other than glucose also play a part in its calculated value, which should be kept in mind before a therapeutic treatment is given.
\end{abstract}

\section{Introduction}

Hemoglobin A1c (HbA1c), also known as glycated hemoglobin can be used as an indicator of a patient's glycemic status for over a previous 3 months (Telen et al., 2004). According to the American Diabetes Guidelines, HbA1c levels is supposed to be maintained below $7 \%$ in the diabetic patients so as to prevent the development of microvascular complications (ADA, 2007).As per the recent recommendations by the IDF and AACE, the optimum level of HbA1c of the diabetics has been brought down to the target of $6.5 \%$. Blood glucose alone is not the cause for changes in the HbA1c levels and can be altered in case of hemolytic anaemias (Horton et al., 1965), haemoglobinopathies 
(Eberentz-Lhomme et al., 1984), acute and chronic blood loss (Bernstein, 1980; Starkman et al., 1983), pregnancy (Lind, 1979; Hanson et al., 1983) and uremia (de Boer et al., 1980; Flückiger et al., 1981; Paisey et al., 1983). Vitamin B12, folate and iron deficiency anaemia have also been shown to affect HbA1c levels (Sinha et al., 2012).

Iron deficiency anemia (IDA) is one of the most prevalent forms of malnutrition. Globally, $50 \%$ of anemia cases are attributed to iron deficiency. The storage form of iron is Ferritin which reflects the iron status of the patient (John, 2008).

Studies have shown that reduced iron stores have a direct link with increased glycation of hemoglobin A1C (HbA1c), thereby leading to false-high values of $\mathrm{HbA1c}$ in the nondiabetic individuals (Brooks et al., 1980).

In the Indian subcontinent also, IDA is found to be the most common type of anemia, especially in the diabetic patients as India is said to be the diabetes capital of the world (Shendurnikaref, 2007). Earlier studies have shown a relationship between IDA and HbA1c. Brooks et al., (1980), Sluiter et al., (1980) and Mitchell et al., (1980) have reported a relation which existed between them and have tried to estimate the HbA1 values in 35 non-diabetic patients with iron deficiency anemia before and after treatment with iron. It was observed that the elevated levels of HbA1c had significantly decreased in these patients after the treatment.

However, no significant difference was found by von Heyningen et al., (1985) and GramHansen et al., (1990) between the HbA1c levels of anaemic patients and controls. Other studies have shown that reduced iron levels are correlated with increased levels of HbA1c leading to false high levels of HbA1c in non- diabetic individuals (Brooks et al., 1980). Though one of the most common cause of nutritional deficiency, there have been many reports of inconsistency in HbA1c levels and the clinical implications (Brooks et al., 1980; Sinha et al., 2012).

Since the earlier results on the relation between $\mathrm{HbA} 1 \mathrm{c}$ and IDA were contradictory and the exact mechanism as well as relationship remains unknown, we have attempted to perform this study to investigate the effects of Iron Deficiency Anaemia on HbA1c levels in the population in or geographical area.

\section{Materials and Methods}

This study was conducted by the department of Biochemistry at Anupama hospital over a period of 2 years since August 2014 September 2016, 98 diabetic patients and 86 non diabetic patients who came to our hospital with anemia were included into the study. Female patients of child bearing age, if found positive for pregnancy were excluded from the study. All the patients were screened for disorders like hemolytic anemias, hemoglobinopathies, and uremia with high creatinine and urea levels and were also excluded if found positive.

The nature of the study was explained in detail to the patients and their relatives and informed consent was obtained from all of them prior to their inclusion into the study. All those who declined to be included or those who left midway were also excluded from the study.

Detailed history and demographic details were taken from all the patients. They were all subjected to thorough physical and clinical examination. Hemoglobin levels, mean corpuscular hemoglobin (MCH), mean corpuscular hemoglobin concentration 
(MHCH), mean corpuscular volume (MCV), hematocrit, platelet count, total blood picture, differential leucocyte count was done for all samples. Samples from patients were tested for serum ferritin and haemoglobin at base line, after 1 week, 1 month and 2 months following iron treatment. Serum ferritin was measured by an ELISA test, while HbA1c levels were measured using the glycohaemoglobin reagent kit which works on the principle of exchange column chromatography.

The anemia type was defined by peripheral smear examination. The type of anemia was divided into mild, moderate and severe based on the hemoglobin levels. Mild anemia was categorized when hemoglobin levels were 12 - $12.9 \mathrm{~g} / \mathrm{dL}$ in males and $11-11.9 \mathrm{~g} / \mathrm{dL}$ in females; moderate anemia with $9-11.9 \mathrm{~g} / \mathrm{dL}$ in males and $8-10.9 \mathrm{~g} / \mathrm{dL}$ in females; severe was $<9 \mathrm{~g} / \mathrm{dl}$ in males and $<8 \mathrm{~g} / \mathrm{dL}$ in females.

Patients with microcytic hypochromic peripheral smear, low hemoglobin levels of $<12 \mathrm{~g} \%$ in males and $11 \mathrm{~g} \%$ in females, predominantly microcytic indices (MCV $<80 \mathrm{fL})$ or hypochromic indices $(\mathrm{MCH}<26$ $\mathrm{pg} /$ cell) were considered to be iron deficient anemia (IDA). IDA was confirmed by serum ferritin levels $<29 \mathrm{ng} / \mathrm{ml}$ in males and $<20$ $\mathrm{ng} / \mathrm{ml}$ in females. The tests for these levels were repeated after 1 month and 2 months.

Measurements: $\mathrm{Hb}, \mathrm{MCV}, \mathrm{MCH}, \mathrm{MHC}$ were estimated by ADVIA 360 analyzer. HbA1c was estimated in Clover HbAlc analyzer by Boronate Affinity Binding Precipitation method. Serum Ferritin was estimated by Ray Bio Human Ferritin ELISA kit.

\section{Results and Discussion}

Out of the total 98 diabetic patients, 42 $(42.9 \%)$ were males and 56 (57\%) were females. Among the non-diabetes also, the predominant gender were females $(58.1 \%)$ and males were 36 (41.9\%) (Table 1).

The most common type of anemia among the diabetic patients was severe, seen in 65 cases $(66.3 \%)$, followed by moderate in $31(31.6 \%)$. Mild was seen only on 2 cases (2\%). However among the non-diabetic patients, most of them had mild anemia with 33 cases (38.4\%) followed by moderate in 30 (34.9\%) of the cases and severe anemia was seen in 23 (26.7\%) of the patients (Table 2).

Weakness was most common symptom seen among175 $(94.1 \%)$ of the patients, followed by malaise in $88.2 \%$ of the patients. Many of the patients were disinterested in their work as seen in 102 (55\%) and dyspnoea was observed in $40.9 \%$ of the patients. Among the women, one of the common complaints for anemia was dysmenorrhagia seen in $21 \%$ of the patients. Among all the patients 54\% were vegetarians and the rest were non vegetarians (Fig. 1).

At baseline the hemoglobin in the anemic patients was $6.3 \mathrm{~g} / \mathrm{dL}$, while the serum ferritin was $7.3 \mathrm{mg} / \mathrm{ml}$ and $\mathrm{HbAlc}$ was $6.2 \%$ and $12.1 \mathrm{~g} / \mathrm{dL}, 259 \mathrm{mg} / \mathrm{ml}$ and $5.1 \%$ respectively after 2 months of treatment with iron supplements. The HbAlc levels showed considerable reduction after the treatment (Table 3).

Diabetes mellitus is a group of metabolic diseases characterized by hyperglycemia and its incidence is sharply increasing worldwide with many long term macrovascular and microvascular complications (Kilpatrick et al., 2009). HbA1c is a glycated hemoglobin that is usually used for assessing the glycemic status of diabetic patient for the previous 3 months. Apart from blood sugar, other conditions such as hemolytic anemias, hemoglobinopathies, acute and chronic blood loss, pregnancy, and uremia have been shown 
to affect HbA1c levels (Lind et al., 1979; there has been tremendous interest in the Starkman et al., 1983; Eberentz-Lhomme et HbA1c levels among patients with anemias al., 1984; Bernstein et al., 1990). Of late, like iron deficiency anemia.

Table.1 Sex wise distribution of HbA1c in patients with and without Diabetes mellitus

\begin{tabular}{|c|c|c|c|c|c|c|}
\hline & \multicolumn{2}{|l|}{ Males } & \multicolumn{2}{|l|}{ Females } & \multicolumn{2}{|l|}{ Total } \\
\hline & $\mathrm{N}(\%)$ & $\begin{array}{l}\text { HbAlc } \\
\text { Levels } \\
(\text { mean } \pm \text { SD) }\end{array}$ & $\mathrm{N}(\%)$ & $\begin{array}{l}\text { HbAlc } \\
\text { Levels } \\
(\text { mean } \pm S D)\end{array}$ & $\mathrm{N}(\%)$ & $\begin{array}{l}\text { HbA1c } \\
\text { Levels } \\
(\text { mean } \pm \text { SD) }\end{array}$ \\
\hline Diabetics & $\begin{array}{l}42 \\
(42.9 \%)\end{array}$ & $7.09 \pm 0.47$ & $56(57 \%)$ & $7.87 \pm 0.66$ & $\begin{array}{l}98 \\
(100 \%)\end{array}$ & $7.46 \pm 0.57$ \\
\hline $\begin{array}{l}\text { Non } \\
\text { Diabetics }\end{array}$ & $\begin{array}{l}36 \\
(41.9 \%)\end{array}$ & $4.63 \pm 0.31$ & $\begin{array}{l}50 \\
(58.1 \%)\end{array}$ & $5.22 \pm 0.49$ & $\begin{array}{l}86 \\
(100 \%)\end{array}$ & $4.81 \pm 0.42$ \\
\hline
\end{tabular}

Table.2 Type of anemia among the patients

\begin{tabular}{|l|l|l|l|l|}
\hline & Mild Anemia & Moderate anemia & Severe anemia & \\
\hline Diabetic & $2(2 \%)$ & $31(31.6 \%)$ & $65(66.3 \%)$ & 98 \\
\hline Non diabetic & $33(38.4 \%)$ & $30(34.9 \%)$ & $23(26.7 \%)$ & 86 \\
\hline
\end{tabular}

Table.3 Hemoglobin, ferritin and HbA1c levels in IDA patients before and after iron treatment

\begin{tabular}{|l|l|l|l|}
\hline & Cases at baseline & Cases after 1 month & Cases after 2 months \\
\hline Haemoglobin $(\mathbf{g} / \mathbf{d L})$ & $6.3 \pm 0.9$ & $9.9 \pm 1.5$ & $12.1 \pm 0.99$ \\
\hline Serum Ferritin $(\mathbf{m g} / \mathbf{m L})$ & $7.3 \pm 3.9$ & $145.6 \pm 44.9$ & $259 \pm 63.1$ \\
\hline HbA1c $(\%)$ & $6.2 \pm 2.1$ & $5.5 \pm 0.9$ & $5.1 \pm 0.7$ \\
\hline
\end{tabular}

Fig.1 Symptoms observed among then patients

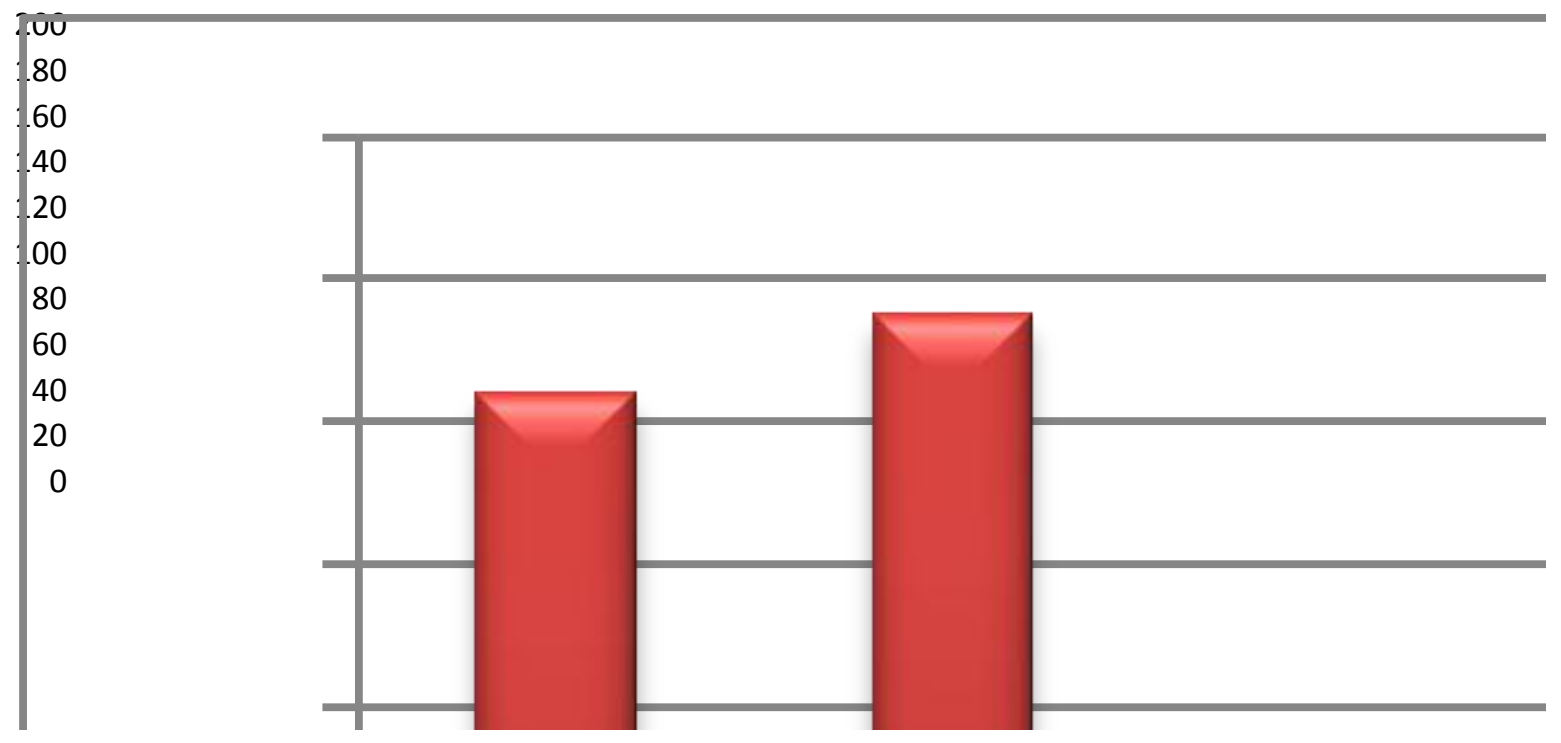


The present study shows the predominance of anemia among the women compared to men, both the diabetics as well as those without diabetes. Similar results were seen in another study by Sinha et al., who also observed IDA to be more prominent among the females rather than males. Christy et al., and Chodeshwari et al., also reported similar results in their studies (Christy et al., 2014; Chowdeswari et al., 2016).

Most of the patients with IDA among the diabetic group had severe anemia while very few had mild anemia. However among the non-diabetic group, most of them had mild anemia while few had severe anemia.

The most common symptoms seen among the patients was weakness $(94.1 \%)$, followed by malaise $(88.2 \%)$, disinterest in work $(54.8 \%)$ and dyspnoea (40.9\%). Bleeding due to dysmenorrhagia in women was observed in $20 \%$ of the patients and worm infestation was seen in $3.2 \%$ of the cases. In a similar study by Bharadwaj et al., $96 \%$ of the patients complained of weakness and malaise in $90 \%$. Dyspnoea was seen in $38 \%$ and disinterest in work was seen in $60 \%$ of the cases. $68 \%$ of their patients were vegetarians and the dietary pattern to be of significant value in the development if IDA. Our study also showed a majority of the patients being vegetarians, though this was not found to be of significance (Starkman, 1983).

In our study, there was a significant reduction in the levels of HbA1c among the patients on treatment with iron supplements. This was first suggested by Brooks et al., (1980) who assessed HbA1c levels in 35 non-diabetic patients having iron deficiency anemia both before and after treatment with iron. They observed that HbA1c levels were significantly higher in iron deficiency anemia patients and decreased after treatment with iron. It was proposed that, in iron deficiency, the quaternary structure of the hemoglobin molecule was altered, and that glycation of the globin chain occurred more readily in the relative absence of iron (Brooks et al., 1980). Some studies also proposed that the glycation of hemoglobin was a permanent process. Thus, the $\mathrm{HbA}_{1} \mathrm{C}$ levels in the RBCs would increase as the cell's age advances. It was also found that after treatment of IDA in patients with normal blood glucose levels, $\mathrm{HbA}_{1} \mathrm{C}$ concentration was reduced because of very young red cells. However if iron deficiency persists for a long time, production of red cells would fall, leading to a higher average age of circulating erythrocytes and therefore increased $\mathrm{HbA}_{1} \mathrm{C}$ levels (Shanthi et al., 2013). However, Ford et al., and Van Heyningen et $a l$, reported no significant relation between the levels of HbA1c and IDA status (Saudek et al., 2008; Ford et al., 2011).

We have thus observed a direct relation between the HbA1c levels and iron deficiency anemia. HbA1c levels were elevated in IDA which reduced with iron supplements. This shows that whenever HbA1c is calculated to detect the glycemic status of a patient, factors other than glucose also play a part in its calculated value, which should be kept in mind before a therapeutic treatment is given.

\section{References}

American Diabetes Association position statement: Standards of medical care in diabetes-2007. Diabetes Care 2007, 30: $1-9$

Bernstein RE. 1980. Glycosylated hemoglobins: hematologic considerations determine which assay for glycohemoglobin is advisable. Clin Chem, 26: 174-175.

Bhardwaj K, Sharma SK, Rajpal N, et al., 2016. Effect of Iron Deficiency Anaemia on Haemoglobin A1c Levels. Ann Clin Lab Res, 4(4):123. 
Brooks AP, Metcalfe J, Day JL, Edwards MS. 1980. Iron deficiency and glycosylated haemoglobin A1. Lancet. Jul; 316(8186): 141.

Chowdeswari N, Jaya N, B.V Rama Rao. 2016. Incidence and Association of Glycated Hemoglobin Levels with Iron Deficiency Anemia in Patients with or without Diabetes - A Study in a Semi Urban Area. International Journal of Clinical Biochemistry and Research, 3(1):124-128.

Christy AL, Manjrekar PA, Babu RP, Hegde A, and Rukmini M.S. 2014. Influence of Iron Deficiency Anemia on Hemoglobin A1C Levels in Diabetic Individuals with Controlled Plasma Glucose Levels. Iranian Biomedical Journal 18(2): 8893.

De Boer M.J., Miedema K., Casparie A.F. 1980. Glycosylated haemoglobin in renal failure. Diabetologia, 18: 437-440.

Eberentz-Lhomme C, Ducrocq R, Intrator S, Elion J, Nunez E, et al., 1984. Haemoglobinopathies: a pitfall in the assessment of glycosylated haemoglobin by ion-exchange chromatography. Diabetologia, 27: 596598.

Flückiger R, Harmon W, Meier W, Loo S, Gabbay KH. 1981. Haemoglobin carbamylation in uremia. N Engl J Med, 304: 823-827.

Ford ES, Cowie CC, Li C, Handelsman Y, Bloomgarden ZT. 20.11. Irondeficiency anemia, non-iron deficiency anemia and HbA1c among adults in the US. J Diabetes. 3(1):67-73.

Gram-Hansen P, Eriksen J, Mourits-Andersen T, Olesen L., 1990. Glycosylated haemoglobin (HbA1c) in iron- and vitamin B12 ĚĞİcŝ̆Ğncy J Intern Med 227: 133-136.

Hanson U, Hagenfeldt L, Hagenfeldt K. 1983. Glycosylated hemoglobins in normal pregnancy: Sequential changes and relation to birth weight. ObstetGynecol 62: 741-744.

Horton BF, Huisman TH. 1965. Studies on the heterogeneity of hemoglobin. VII. Minor hemoglobin components in haematological diseases. Br J Haematol 11: 296-304.

John A. Iron Deficiency and Other Hypoproliferative Anemias. In: Longo D, Fauci A, Kasper D, Hauser S, Jameson J, Loscalzo J, editors. Principles of Internal Medicine by Harrisons, 17th ed. United States of America. McGraw-Hill; 2008. p. 62835.

Kilpatrick ES, Bloomgarden ZT, Zimmet PZ. 2009. Is haemoglobin A1c a step forward for diagnosing diabetes. BMJ. 339: b4432.

Lind T, Cheyne GA. 1979. Effect of normal pregnancy upon the glycosylated haemoglobins. Br J ObstetGynaecol 86: 210-213.

Mitchell TR, Anderson D, Shepperd J. 1980. Iron deficiency haemochromatosis, and glycosylated haemoglobin. Lancet 2: 747.

Paisey R, Banks R, Holton R, Young K, Hopton M, et al., 1986. Glycosylated haemoglobin in uraemia. Diabet Med 3: 445-448.

Saudek CD, Herman WH, Sacks DB, Bergenstal RM, Edelman D, Davidson MB. 2008. A new look at screening and diagnosing diabetes mellitus. J Clin Endocrinol Metab. 93(7): 2447-53.

Shanthi B, Revathy C, Manjula Devi AJ, et al. 2013. Effect of iron deficiency on glycation of haemoglobin in nondiabetics. J Clin Diagn Res. 7(1): 15-17.

Shendurnikaref $\mathrm{N}$ (Ed). Iron deficiency is preventable. [Updated on Apr 2007]

Sinha N, Mishra TK, Singh T, Gupta N. 2012. Effect of Iron Deficiency Anemia on 
Hemoglobin A1c Levels Ann Lab Med. 32(1): 17-22.

Sluiter WJ, van Essen LH, Reitsma WD, Doorenbos H. 1980. Glycosylated haemoglobin and iron deficiency. Lancet 2: 531-532.

Starkman HS, Wacks M, Soeldner JS, Kim A. 1983. Effect of acute blood loss on glycosylated hemoglobin determinations in normal subjects. Diabetes Care 6: 291-294.
Telen MJ and Kaufman RE. The mature erythrocyte. In: Greer JP, Forester J, et al., eds. Wintrobe's clinical hematology. 11th ed. Lippincot Williams and Wilkins, 2004:230

Van Heyningen C, Dalton RG. 1985. Glycosylated haemoglobin in Ğncyanaemia. Lancet, 1: 874.

\section{How to cite this article:}

Vydehi Veeramalla and Swetha Madas. 2017. Correlation of Glycated Hemoglobin and Iron Deficiency Anemia among Diabetic and Non Diabetic Patients. Int.J.Curr.Microbiol.App.Sci. 6(12): 2669-2675. doi: https://doi.org/10.20546/ijcmas.2017.612.308 